Article

\title{
Spatiotemporal Distribution and Species Composition of Fish Assemblages in the Transitional Zone of the Three Gorges Reservoir, China
}

\author{
Pengcheng Lin ${ }^{1,2}$, Lin Chen ${ }^{1}$, Xingchen Gao ${ }^{2}$, Chunling Wang ${ }^{1}$, Xin Gao ${ }^{1, *}$ \\ and Myounghee Kang ${ }^{3, *}$ \\ 1 Institute of Hydrobiology, Chinese Academy of Sciences, Wuhan 430072, China; linpc@ihb.ac.cn (P.L.); \\ 18780044276@163.com (L.C.); chwang@ihb.ac.cn (C.W.) \\ 2 Hubei Key Laboratory of Three Gorges Project for Conservation of Fishes, \\ Chinese Sturgeon Research Institute, China Three Gorges Corporation, Yichang 443000, China; \\ gaoxingchen_hi@126.com \\ 3 Department of Maritime Police and Production System, Institute of Marine Industry, \\ Gyeongsang National University, Tongyeong 650-912, Korea \\ * Correspondence: gaoxin@ihb.ac.cn (X.G.); mk@gnu.ac.kr (M.K.)
}

Received: 27 October 2020; Accepted: 10 December 2020; Published: 14 December 2020

\begin{abstract}
The river-reservoir transitional zones play an important role in maintaining riverine fish biodiversity and abundance in highly regulated rivers. The Upper Yangtze River, which contains 286 fish species, is experiencing intense hydropower development. However, few studies have been conducted on the spatial distribution of fish in the river-reservoir transitional zones in the Upper Yangtze River, and it is therefore difficult to predict how this development will impact the region. In this study, a $200-\mathrm{kHz}$ split-beam acoustic system in combination with biological samplings was used to investigate the composition and spatiotemporal distribution of the fish in the transition zone of the Three Gorges Reservoir (TGR) in 2017. The biological samplings comprised 7434 individuals from 61 species, 38 genera, 15 families, and 5 orders. The dominant fish species were Rhinogobio cylindricus, Coreius guichenoti, Hemiculter bleekeri, and Pelteobagrus vachelli. Acoustic detection identified the mean target strength (TS) to be -55.6 in May, -57.8 in August, and $-55.8 \mathrm{~dB}$ in December. Accordingly, the average fish density was $4.96,6.96$, and $4.42 \mathrm{ind} / 1000 \mathrm{~m}^{3}$. Significant differences were found in the TS and fish density between flood season (August) and non-flood season (May and December). Spatially, fish preferred the meandering sections at 10-20 m deep. A size-dependent vertical distribution pattern was observed, with larger fish in the deeper layers and smaller fish in shallower waters. Lastly, our results suggest that meandering deep channels should be assigned high priority with respect to fish conservation in the Upper Yangtze River.
\end{abstract}

Keywords: fish distribution; hydroacoustic; environmental variables; Upper Yangtze River; Three Gorges Reservoir

\section{Introduction}

Understanding the spatial distribution of fish is a major theme in freshwater ecology. It not only enhances our understanding of the relationship between fish species and relevant environments, but also allows scientists to identify critical habitats, and collect essential information to formulate effective freshwater fishery management and conservation strategies [1]. Past studies of freshwater fish in streams and rivers have led to a generalized understanding that freshwater fish assemblages are structured in part by local channel structure and hydraulic conditions in temperate regions [2-4]. The structural heterogeneity of a river channel, determined by the presence of bends and pools, 
may attract fish [3]. Water temperature, a fundamental property of fish habitats, affects stream metabolism, and fish bioenergetics, and can thus structure fish communities. Anthropogenic activities, such as the construction of huge dams and changes in land use, can also alter channel morphology and affect the temporal distribution of thermally-suitable habitats [4]. In highly regulated rivers, dams and reservoirs alter the riverine environment through inundation, hydrologic alteration, and fragmentation, which may shift fish distributions and modify fish assemblages [5]. Previous studies have reported that lake and river fish can coexist in the transitional zone where the hydrological regime frequently switches due to operations related to reservoirs [6,7]. However, most studies have focused on the fish distribution at the reservoir or larger watershed scales, whereas little attention has been paid to the reach or local scales [8].

Several monitoring techniques can be used to display the spatial distribution of fish, such as net catching, electrofishing, hydroacoustics, and underwater video [9]. Of these, the hydroacoustic method is a repeatable and noninvasive approach to studying fish size, abundance, and spatial distribution in waters [9-11]. The rapid development and wide application of geostatistics have allowed hydroacoustics coupled with Geographic Information Systems (GIS) to create a high-resolution map of the spatial distribution of fish $[8,11]$. However, hydroacoustic techniques have limitations-e.g., they cannot identify species. To accurately evaluate the abundance and spatiotemporal distribution of fish, a combination of hydroacoustic methods and net sampling should be employed.

Geographically, hydroacoustic research in freshwater ecosystems is mainly concentrated in North America and Europe [11]. Although the Upper Yangtze River is a global biodiversity hotspot that harbors 286 fish species [12], few studies have applied hydroacoustic methods there [13-16]. Fish biodiversity and resources in the Upper Yangtze River have sharply declined in recent years, mainly due to widespread hydropower development in the basin [17-19]. The Three Gorges Reservoir (TGR) behind the Three Gorges Dam (TGD) is one of the largest reservoirs in the world. Results from model analysis and empirical monitoring showed that TGR has a significant impact on the distribution and abundance of riverine fish [5,17]. Fish diversity declined and the fish species endemic to the Upper Yangtze River-e.g., Acipenser dabryanus, Leptobotia elongata, Ancherythroculter wangi, Megalobrama elongata, Onychostoma brevis, and Ctenogobius szechuanensis-nearly disappeared in the lacustrine zone of the TGR, which runs $524 \mathrm{~km}$ in length upstream from the TGD. On the contrary, fish richness in the transitional zone of TGR has significantly increased by $24.2 \%$ after impoundment [20], which indicated that this area played an important role in maintaining fish resources in the Upper Yangtze River.

In this study, a combination of the hydroacoustic method with biological sampling was used to investigate fish in the transitional zone of the TGR in 2017. We aimed to (i) investigate the species composition and quantify fish density, (ii) assess the distribution of fish in the longitudinal and vertical dimensions, and (iii) identify which elements-e.g., channel morphology, water depth, and water temperature-impacted the fish distribution in the transitional zone. Our results will present spatiotemporal distribution patterns of fish assemblages in the regulated river and provide suggestions for reservoir management and conservation strategies.

\section{Materials and Methods}

\subsection{Study Area}

The transitional zone of the TGR is $140 \mathrm{~km}$ long and comprises the reach of the Upper Yangtze River from Changshou to Jiangjin District, Chongqing City. The study area covered the Mudong reach (Yuzui to Maliu), which is $20 \mathrm{~km}$ long and 350-1200 $\mathrm{m}$ wide and is located downstream of Chongqing City (Figure 1). In the study area, two sections were categorized based on channel morphology: An upstream meandering section from Yuzui to Mudong (tortuosity coefficient of 1.35) and a downstream straight section from Mudong to Maliu (tortuosity coefficient of 1.04). Historically, the Mudong reach has ecological functions that are important for the Upper Yangtze fisheries; in particular, it serves as a spawning ground for four major species of Chinese carp and a nursery area for a number of native 
species [7,21,22]. Since 2008, the Mudong reach has been inundated during the dry period (October to April) due to a 175-m above sea level (ASL) experimental impoundment from the Three Gorges Dam (TGD), and has maintained a natural flowing regime during the flooding season (May to September). In 2017, the TGR began to impound with an initial water level of $153.50 \mathrm{~m}$ ASL on 10 September and reached the normal impoundment water level of $175 \mathrm{~m}$ ASL on October 21.

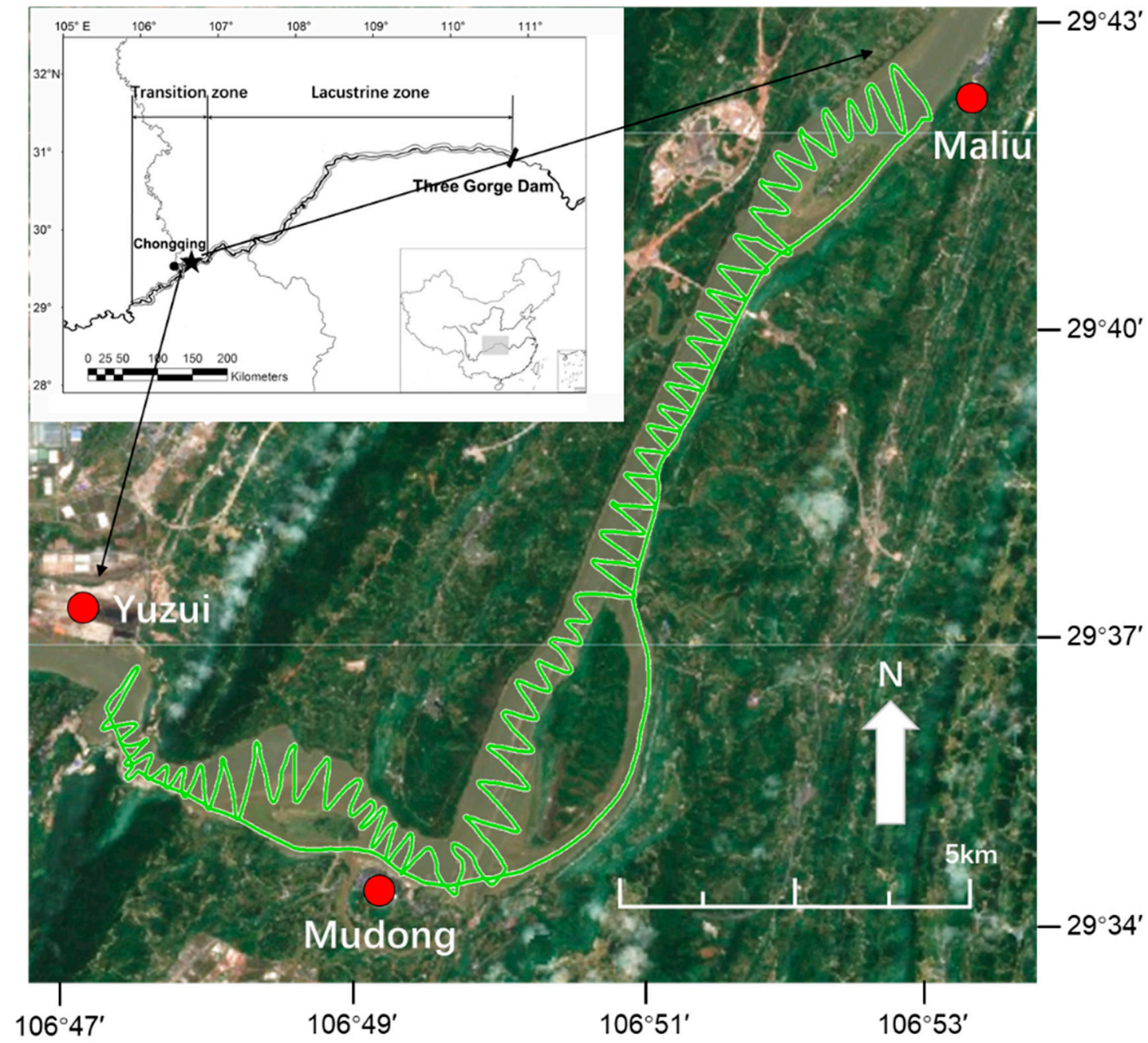

Figure 1. Map of the study area in the Mudong reach located in the transitional zone of the Three Gorge Reservoir. The green zigzag line represents the hydroacoustic transect line. The star mark in black on the upper left panel indicates the study area. The black and red dots indicate major cities and towns.

\subsection{Environmental Data Collection}

The data on water levels and daily discharges were obtained from the Cuntan hydrologic station [23]. The HOBO Water Temp Pro v2 logger (model U22-001; Onset Computer Corporation, Bourne, MA, USA) was deployed at a dock near Mudong Town and measured the water temperature at a depth of $1 \mathrm{~m}$. The logger automatically collected data at 4-h intervals for all of 2017. Water depths were obtained based on acoustic data and we used interpolation to convert the depth point data into a raster data layer in ArcGIS (ver. 9.3, Esri, Redlands, CA, USA).

\subsection{Hydroacoustics Surveys}

Three mobile hydroacoustic surveys were conducted in 22-23 May, 30-31 August, and 9-10 December 2017 (Table 1). Each survey was performed during the day (9:00 to 18:00) because water traffic makes it dangerous to survey at night. The hydroacoustic system was a Simrad EY60 
echosounder with a split-beam transducer (Simrad ES200-7C, Kongsberg Maritime, Kongsberg, Norway) with vertical pointing beam. The transducer was set to $200 \mathrm{kHz}$ with a nominal beam angle of $7^{\circ}$. The transducer was vertically mounted to the right side of a 13-m-long fishing boat and positioned at a depth of $50 \mathrm{~cm}$. The echosounder was controlled by Simrad ER 60 acquisition software (version 2.4.0), which provided a real-time display and stored acoustic raw data. Simultaneously, the geographical coordinates were recorded by a GPS (Garmin $72 \mathrm{H})$ connected to the processor. The GPS was accurate to $3 \mathrm{~m}$. The survey was performed on zigzag transect lines at a vessel speed of $8-10 \mathrm{~km} / \mathrm{h}$. Before the field survey, the acoustic system was calibrated with a standard $23 \mathrm{~mm}$ copper sphere according to the standard procedure [24]. The echosounder was set to: Power $=180 \mathrm{~W}$, ping rate $=5 \mathrm{ping} / \mathrm{s}$, and pulse duration $=128 \mu$ s. The coverage coefficient-i.e., the total length of the transect lines divided by the square root of the area-was calculated for each survey to determine whether the survey lines were enough to cover the study area [25]. The total length of the transect lines ranged from 70 to $94 \mathrm{~km}$ and the coverage coefficient was $>14$, meaning that it met the coefficient of variation for estimating fish density or fish abundance [26,27].

Table 1. Parameters of environment and hydroacoustic surveys at the Mudong reach.

\begin{tabular}{cccccc}
\hline $\begin{array}{c}\text { Sampling } \\
\text { Period }\end{array}$ & $\begin{array}{c}\text { Average Water } \\
\text { Depth }(\mathbf{m})\end{array}$ & $\begin{array}{c}\text { Maximum Water } \\
\text { Depth }(\mathbf{m})\end{array}$ & $\begin{array}{c}\text { Water } \\
\text { Temperature }\left({ }^{\circ} \mathbf{C}\right)\end{array}$ & $\begin{array}{c}\text { Total Sailing } \\
\text { Distance }(\mathbf{k m})\end{array}$ & $\begin{array}{c}\text { Degree of } \\
\text { Coverage }\end{array}$ \\
\hline 22-23 May & 13.1 & 60.0 & 21.6 & 70.9 & 14.5 \\
30-31 August & 20.4 & 81.0 & 25.7 & 70.2 & 14.4 \\
9-10 December & 23.9 & 73.0 & 15.1 & 93.5 & 19.2 \\
\hline
\end{tabular}

\subsection{Biological Samplings}

Biological sampling was conducted in spring (13-29 May) and autumn (26 September-9 October) of 2017 (Table 2). Biological sampling could not be implemented in August during the flood season. After the impoundment of TGR in September, fish composition and assemblage structures were similar between October and December based on the monthly investigations by Yang et al. [28]. The biological sampling conducted in October was considered to be close to the acoustic data in terms of time. Gillnets (mesh sizes of 4,6, and $8 \mathrm{~cm}$ ) and a trawl net (net mouth of 10-m wide and 2-m high) were used. Drift gillnets and the trawl net were used during the day (6:00-18:00) and fixed gillnets were used to sample nearshore fish in shallow waters at night (18:00-6:00). Biological sampling was performed by local experienced fishermen in different types of habitats such as pools, riffles, backwaters, and runs. Fish species were identified and the ecological groups (rheophilic, eurytopic, and limnophilic) were classified based on previous studies $[17,20,29]$. Then, the total length (TL, mm) and body mass (W, g) of sampled fish were measured. At least 30 individuals of each species were measured. If the number of fish caught was less than 30 , then all the individuals were measured.

Table 2. Summary of fish biological samplings at the Mudong reach.

\begin{tabular}{ccc}
\hline Sampling Period & Total Mass (kg) & Number of Boat Days \\
\hline 13-29 May & 199.2 & 31 \\
26 September-9 October & 193.1 & 24 \\
\hline
\end{tabular}

\subsection{Acoustic Data Analysis}

The acoustic raw data were converted and analyzed using the Sonar 5-Pro software (version 5.9) [30]. A minimum display threshold on amplitude echogram was set to $-70 \mathrm{~dB}$ - which is commonly used for unknown fish species in various waters worldwide-and a time-varied-gain (TVG) of $40 \log (\mathrm{R})$ was used for target strength (TS) values [31]. An exclusion zone of $0.5 \mathrm{~m}$ above the river bottom was used to avoid false echoes from the bottom. Furthermore, data from the surface to 2-m deep were filtered through a straight line due to the movement of vessels and the existence of a "near-field." Various noises 
were removed using the noise erasing tool in the software, and then manually scrutinized. First of all, single echoes were detected using a single echo detection (SED) algorithm with the minimum TS threshold of $-70 \mathrm{~dB}$, received echo length ( 0.5 to 1.8 times of transmitted pulse length) and the maximum beam compensation of $3 \mathrm{~dB}$ which was very close to the beam axis. In particular, the minimum TS threshold was set because we tried to obtain even small sized fish. Then, tracked fish were determined by the following criteria: No. echoes $\geq 4$, max ping gap $=2$ pings, and gating range $=0.3 \mathrm{~m}$. To confirm fish tracks, each track was visually examined to ensure that tracks contained a series of contiguous single echoes in the same direction of movement in a horizontal plane of the beam [32]. All fish tracks containing mean TS and mean depth were exported for further analysis.

Since a TS-fish length relationship for the Upper Yangtze River fish species was not available, TS ( $\mathrm{dB}$ re $1 \mathrm{~m}^{-2}$ ) was calculated using an empirical formula for carps in dorsal aspect [33]:

$$
\text { TS }=23.97 \log _{10} \mathrm{TL}-103.9
$$

where TL is the total length of an individual fish (mm). In fact, the formula was quantified at $120 \mathrm{kHz}$. For targeting carp species, a TS-fish length equation at $200 \mathrm{kHz}$ was not available, although its horizontal ex situ TS was measured [34]. For capelin, pollock, Pacific Ocean perch, and jellyfish, their frequency response patterns were similar, between 120 and $200 \mathrm{kHz}$ [35]. On the basis of the general schematic description of the relative frequency response based on acoustic categories at frequencies 18-200 kHz, swimbladder-bearing fish such as carps are characterized by constancy between low frequencies (the Rayleigh scattering region) and high frequencies (the geometric scattering region) [36,37]. Thus, the sound scattering strength between 120 and $200 \mathrm{kHz}$ for the species might be similar, which allowed us to use Equation (1).

Fish density $\left(\rho_{v}\right)$ was calculated based on the following formula [30]:

$$
\rho_{v}=\frac{S_{v}}{\bar{\sigma}_{b s}}
$$

where $S_{v}$ is the volume backscattering coefficient $\left(\mathrm{dB}\right.$ re $\left.1 \mathrm{~m}^{2} / \mathrm{m}^{3}\right)$, and $\bar{\sigma}_{b s}$ is the mean backscattering cross-section $\left(\mathrm{m}^{2}\right)$ that is the linear domain of TS.

The spatial distribution of fish density was mapped using kriging interpolation in ArcGIS (ver. 9.3, Esri). The study area (20 km from Yuzui to Maliu, moving downstream) was divided into 10 sections of $2 \mathrm{~km}$ each to further analyze the longitudinal distribution pattern of fish density.

\subsection{Statistical Analyses}

A chi-square test was applied to investigate the difference in weights of fish ecological groups between May and October. Fish length (both measured and converted lengths), density, and target depth were examined for the assumption of normality using the Kolmogorov-Smirnov test. Since the data were abnormally distributed, the differences in the size distribution from net catches between May and October were investigated using a nonparametric Kruskal-Wallis $H$ test. In addition, the fish length and density converted from acoustic data and target depth were examined using a Kruskal-Wallis $H$ test followed by post hoc multiple comparisons to determine which month had significantly different results. Regression analysis was used to understand the relationship between TS and target depth. Statistical analyses were performed using SPSS (version 22.0, IBM) and a $p<0.05$ was considered significant. Graphs were plotted using ArcGIS and Origin (2018, OriginLab, Northampton, MA, USA).

\section{Results}

\subsection{Environmental Factors}

The average monthly discharge in the Mudong reach in 2017 was lowest in January $\left(4304 \mathrm{~m}^{3} / \mathrm{s}\right)$ and highest in August $\left(17,897 \mathrm{~m}^{3} / \mathrm{s}\right)$. Discharge during the flooding period (May-September) was 
5250-29,500 $\mathrm{m}^{3} / \mathrm{s}$, peaking on 27 August, while discharge during the non-flood period (October-April) was $3290-22,800 \mathrm{~m}^{3} / \mathrm{s}$, peaking on 1 February (Figure 2). During the periods of hydroacoustic surveys, the average water temperature increased gradually from 21.6 in May to $25.7^{\circ} \mathrm{C}$ in August, and then sharply declined to $15.1^{\circ} \mathrm{C}$ in December. The average water depth was 13.1 in May, 20.4 in August, and $23.9 \mathrm{~m}$ in December. The average water depth was highest in December because of the impoundment from the TGR (Table 1).

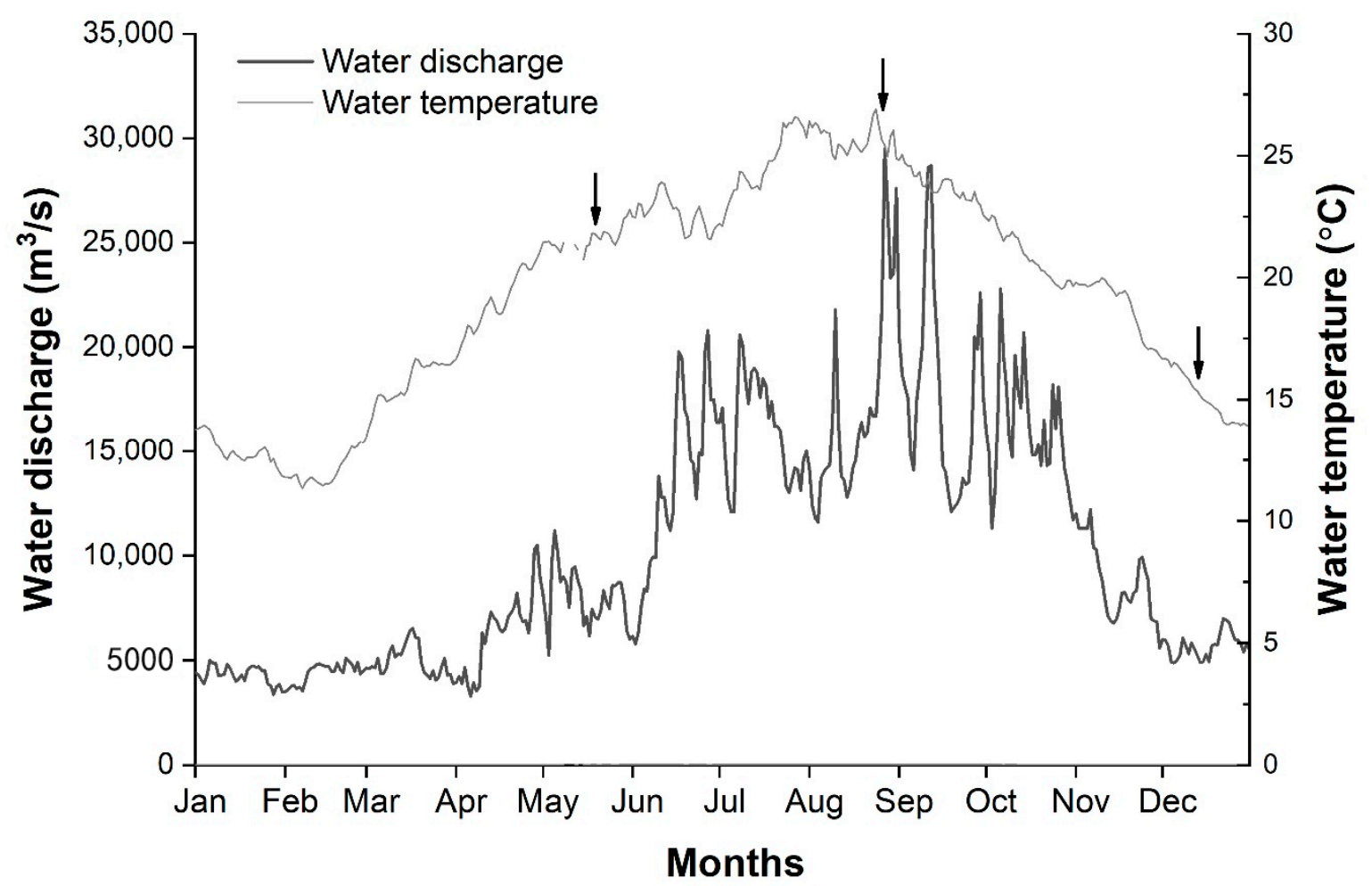

Figure 2. Water discharge and water temperature in the Mudong reach in 2017. Arrows indicate the hydroacoustic surveys.

\subsection{Species Composition and Assemblage Structure}

The total mass in May and October was $392.3 \mathrm{~kg}$ (Table 2). A total of 7434 individuals were identified, belonging to 61 species from 38 genera, 15 families, and five orders (Table 2). Cyprinidae of the fish species was the most common group of fish $(49.2 \%)$ followed by Cobitidae $(14.8 \%)$ and Bagridae (13.1\%). Thirteen fish species endemic to the Upper Yangtze River and four exotic species were collected (Table 3). The dominant species was Rhinogobio cylindricus, accounting for $43.5 \%(W \%)$ in May and 43.6\% in October. Seven species-R. cylindricus, Coreius heterodon, Hemiculter bleekeri, Leiocassis crassilabris, Squalidus argentatus, H. leucisculus, and L. longirostris-accounted for $86.1 \%$ of the total mass in May. Nine species-R. cylindricus, Cyprinus carpio, C. heterodon, Silurus asotus, Hypophthalmichthys molitrix, S. meridionalis, R. typus, Carassius auratus, and Pelteobagrus vachelli-contributed $86.6 \%$ of the total mass in October (Table 3).

A chi-square test revealed that the relative biomasses of fish groups were significantly different between May and October $\left(\chi^{2}=1304.4, p<0.05\right)$. In May, rheophilic fish accounted for $67.7 \%$ of the total biomass and limnophilic fish accounted for $20.8 \%$; however, the rheophilic species declined to $63.0 \%$ and the limnophilic species increased to $25.7 \%$ in October. 
Table 3. Percentages by mass and number of fish, mean total length and mass, and ecological group based on fish species from biological samplings.

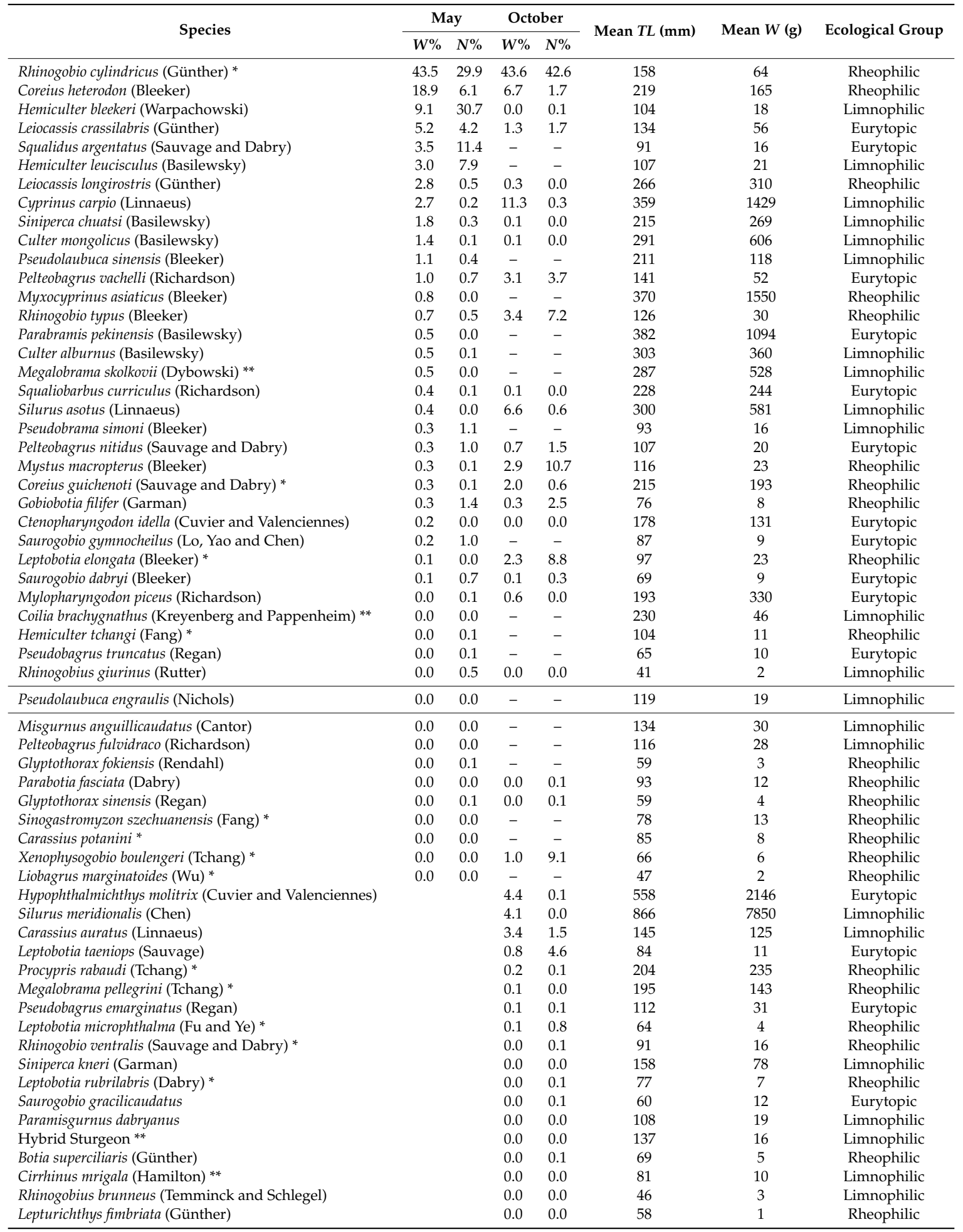

N: Percentage by number; W: Percentage by mass; TL: Total length; W: Body mass; “*” indicates an endemic fish species; "**" indicates an exotic fish species.

\subsection{Biological and Acoustic Fish Lengths}

The average and standard deviation (SD) of total length from biological samplings in May was $15.0 \pm 5.1 \mathrm{~cm}$, ranging from 2.3 to $51.5 \mathrm{~cm}$, and that of total length in October was $13.4 \pm 6.1 \mathrm{~cm}$, 
ranging from 2.4 to $86.6 \mathrm{~cm}$. The length-frequency distribution between the two months was significantly different $(H=166.1, p<0.05)$. The proportion of individuals with $\mathrm{TL}<10 \mathrm{~cm}$ was lower in May (20.3\%) than October (35.6\%), whereas the proportion of individuals with TL $=10-20 \mathrm{~cm}$ was higher in May (65.5\%) than October (53.1\%; Figure 3a).

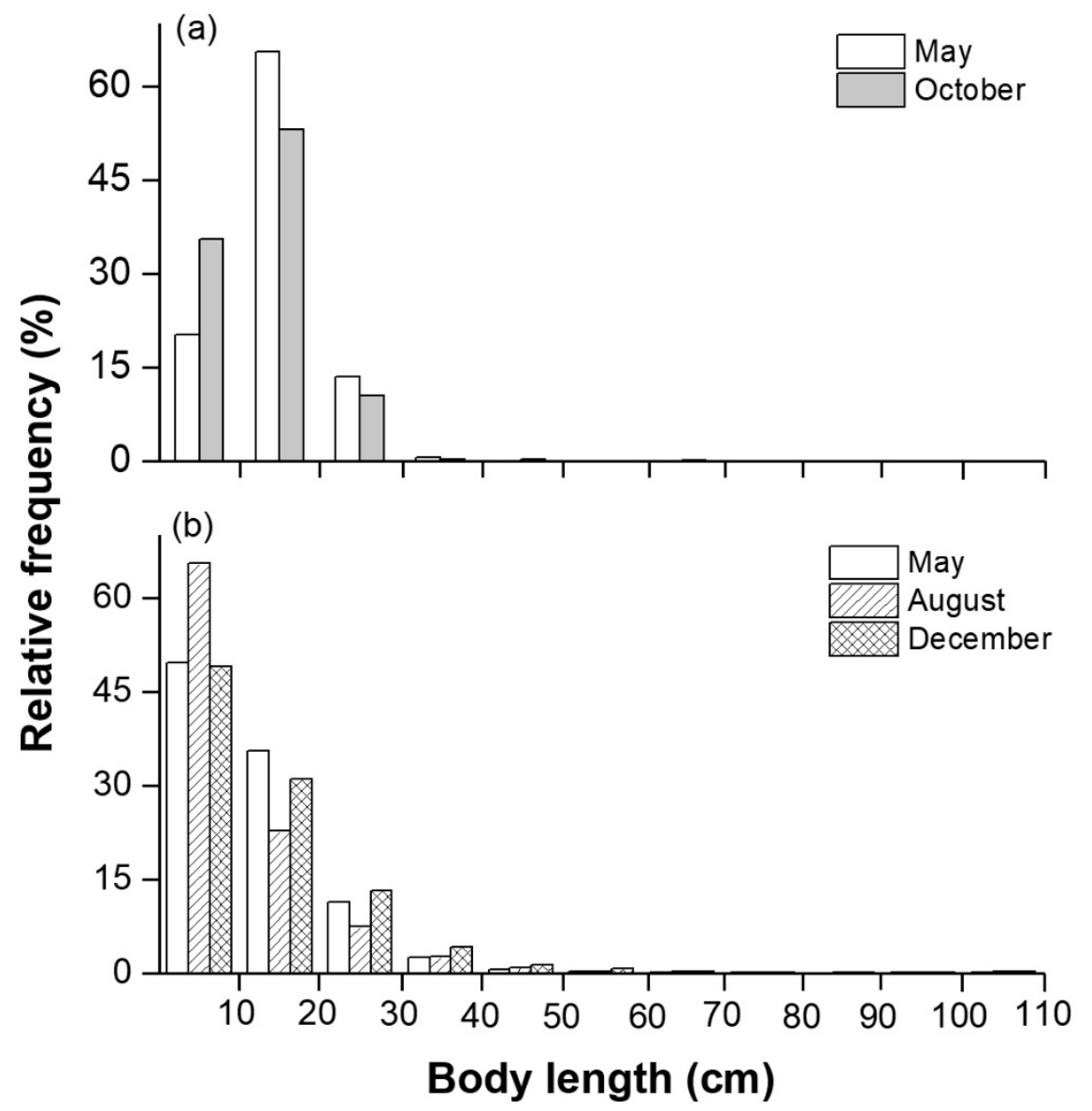

Figure 3. Fish length distribution from net catches (a) and converted acoustic target strength (b).

The average and SD of target strength (TS) values in May, August, and December were $-55.6 \pm 6.2$, $-57.8 \pm 6.9$, and $-55.8 \pm 7.7 \mathrm{~dB}$, respectively. The converted fish lengths from Equation (1) for the three months were $12.5 \pm 8.9,10.9 \pm 11.0$, and $13.5 \pm 12.0 \mathrm{~cm}$, respectively (Figure $3 \mathrm{~b}$ ). We compared the measured lengths from the biological samples and found that the fish lengths converted from acoustic data had a relatively wide size spectrum. Length-frequency distributions were also significantly different among the three months $(H=574.8, p<0.05)$. The proportion of individuals with $\mathrm{TL}<10 \mathrm{~cm}$ was higher in August (65.5\%) than May (49.6\%) or December (49.0\%) (post hoc multiple comparison, $p<0.05$; Figure 3b).

\subsection{Longitudinal and Vertical Distributions of Fish}

In the Mudong reach, the average and SD of fish density was 5.0 $\pm 18.1 \mathrm{in} \mathrm{May,} 7.0 \pm 13.4$ in August, and $4.4 \pm 11.6 \mathrm{ind} / 1000 \mathrm{~m}^{3}$ in December. Fish density was significantly different among the three months $(H=483.1, p<0.05)$, and the fish density during the flooding period was significantly higher than that during the non-flooding period (post hoc multiple comparison, $p<0.05$ ). Longitudinally, the distribution of fish in the Mudong reach was patchy (Figures 4 and 5). The highest density was observed in Section 1 for all three months, followed by Section 3 in August and Section 2 in May (Figure 4). Fish had the most even distribution in August, which is the natural flooding period. In December, when the water temperature dropped, fish were found to be aggregated in Sections 1 and 
3 (Figure 5 and Table 1). Overall, the fish density was considerably higher in the meandering sections upstream than in the relatively strait sections downstream. A strong positive correlation was observed between fish densities and average water depth in each section $(p<0.05)$.

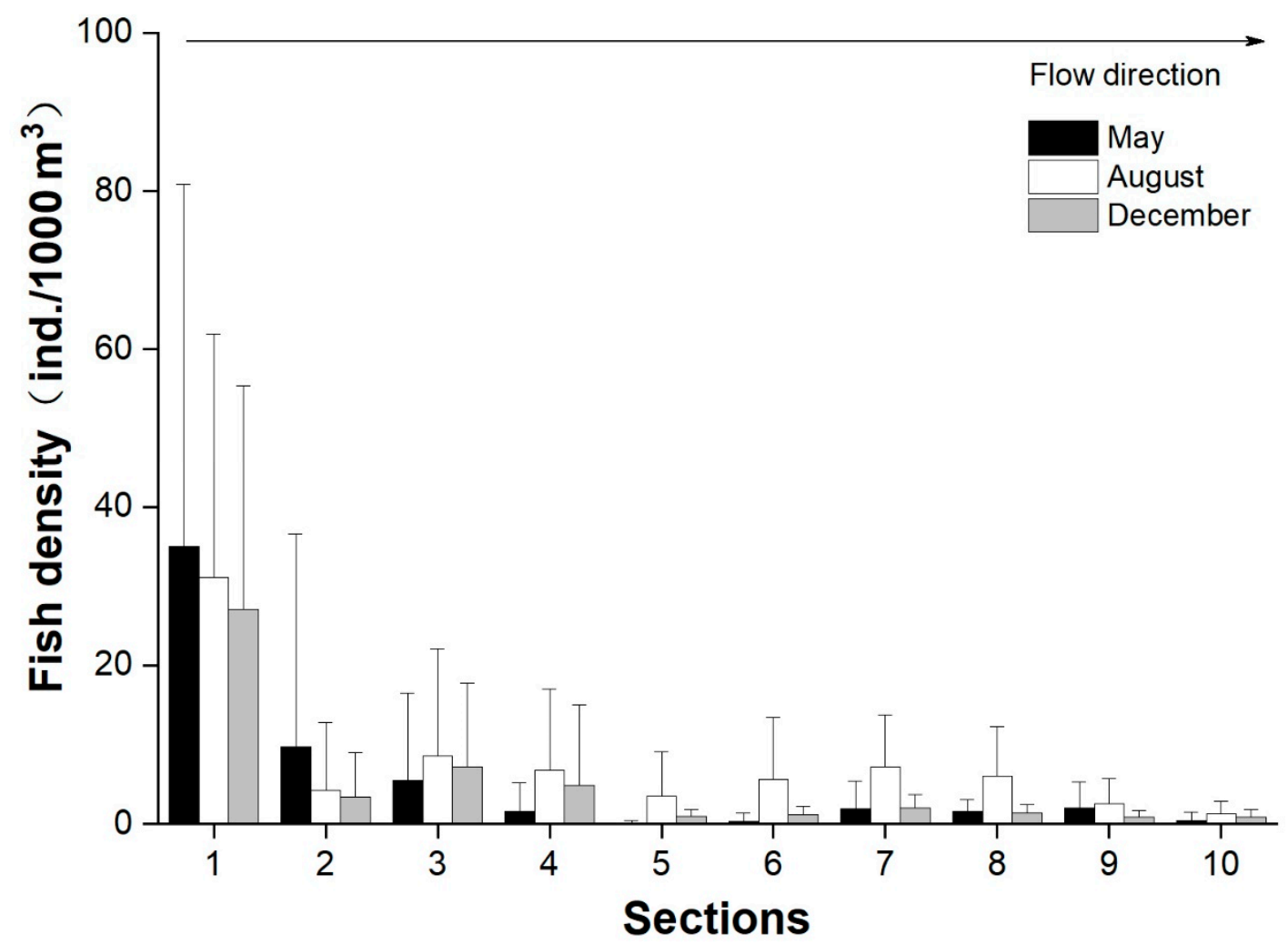

Figure 4. Fish density in the Mudong reach in relation to the flow direction in May, August, and December. The 20-km Mudong reach was divided into 2-km-long sections.

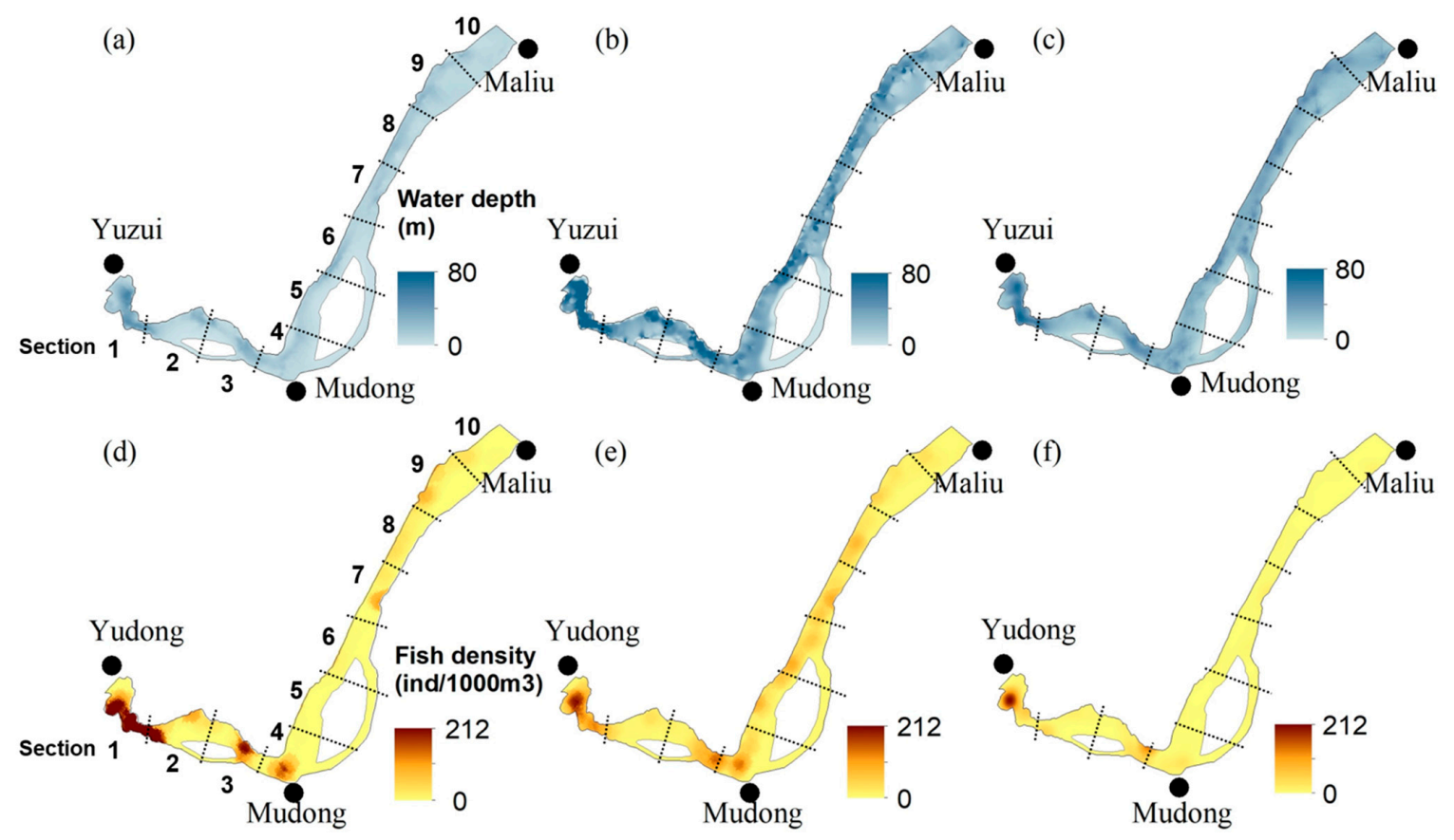

Figure 5. Interpolated water depth ( $\mathrm{m}$, above) and fish density (ind./1000 $\mathrm{m}^{3}$, below) in Mudong reach. The left panels are in May $(\mathbf{a}, \mathbf{d})$, middle in August $(\mathbf{b}, \mathbf{e})$, and right in December $(\mathbf{c}, \mathbf{f})$. Ten sections were marked by dividing the 20-km-long Mudong reach into 2-km-long sections in the flow direction. 
The average \pm SD of the target depth was $14.2 \pm 5.9$ (range 2.1-53.9) in May, $15.2 \pm 9.5$ (range 2.0-79.1) in August, and $21.0 \pm 8.6 \mathrm{~m}$ (range 2.1-69.6 m) in December (Figure 6). A range of 45.2-65.2\% of the individuals detected over the three months was found at 10-20 m deep. Significant differences were also found when comparing the target depth among the three months $(H=2037.0, p<0.05)$. The target depth in December was significantly higher than that in May and August (post hoc multiple comparisons, $p<0.05)$, and no significant difference occurred between May and August. The target depth was highest in December, indicating that fish preferred overwintering in deeper waters. The relationship between target strength and target depth is shown in Figure 6. The greater the target depth, the larger the TS became $(p<0.05)$, indicating a size-dependent vertical distribution pattern in which larger fish resided in deeper water and smaller fish resided in shallower water.
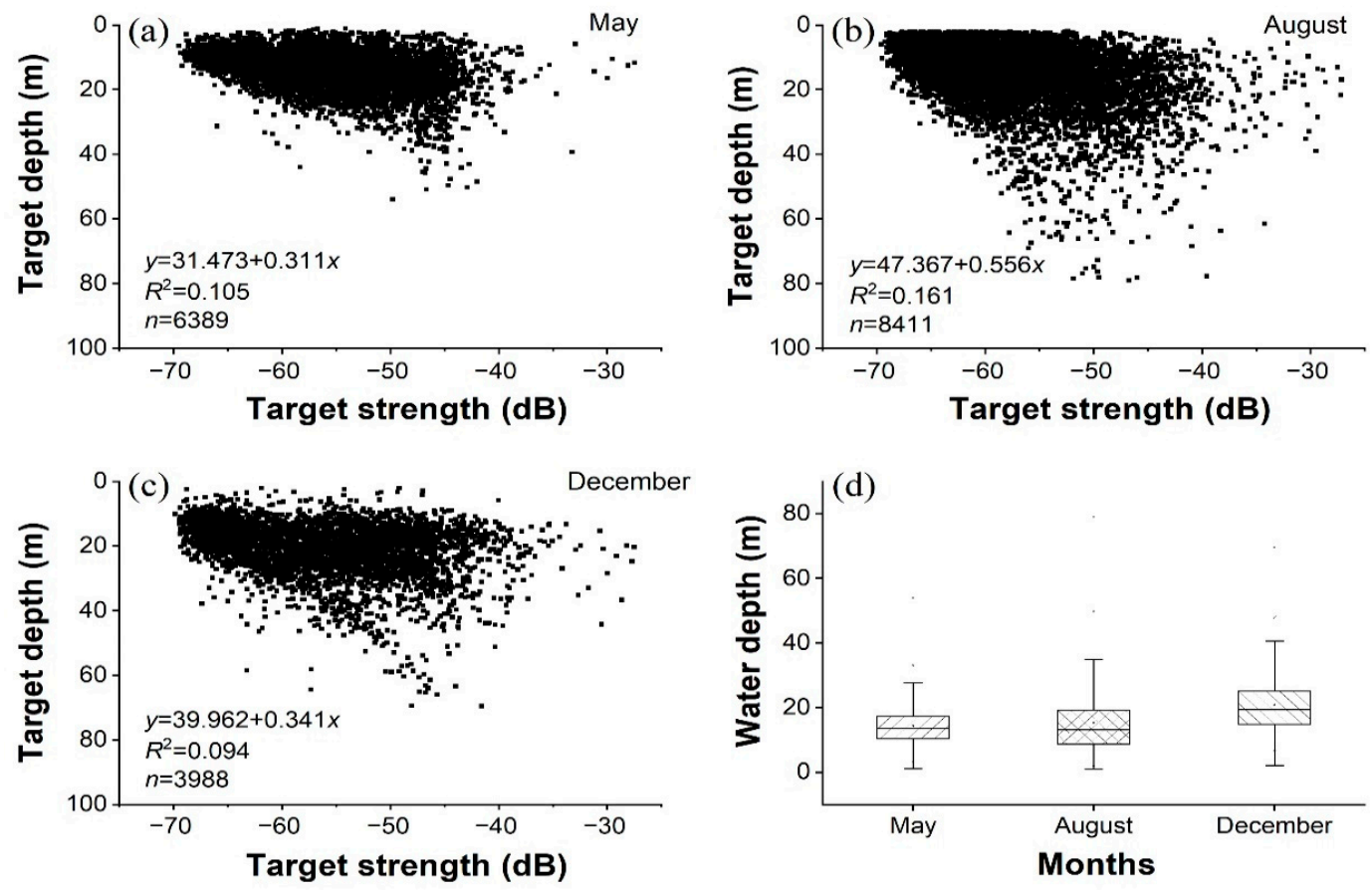

Figure 6. Scatter plots of target strength against target depth in May (a), August (b), and December (c). Water depth for three months (d) is shown with a boxplot.

\section{Discussion}

\subsection{Fish Distribution and Relevant Environmental Factors}

This study is the first to reveal the spatial distribution of fish in the transitional zone of the Three Gorges Reservoir (TGR) using a hydroacoustic technique. The highest fish density was clearly observed in Section 1 (near Yuzui) for all three months. More patches and higher fish density occurred during the flooding season (August).

Variations in the spatiotemporal distribution of fish can be attributed to abiotic, biotic, and anthropogenic factors such as water temperature, water depth, channel morphology, substrate composition, flow velocity, and dam impoundment [38-41]. There are several factors that may explain this fish distribution in the Mudong reach.

First, channel morphology was an important element affecting the distribution of aquatic biota because it governed habitat quality, particularly the in-stream habitat complexity and food abundance. Meandering channels form diverse longitudinal and cross-sectional profiles. Such diverse bathymetric features produce habitat heterogeneity with high hydrological variability and diversity in substrate types, such as a lateral gradient of depth from shallow to deep areas and repeated structures of pools and riffles, where the sedimentation of suspended particles, including drifting forage organisms, takes place [42]. Field studies and river restoration case studies have shown that a large variety of 
habitat conditions and sufficient food provisions at such areas support high diversity and abundance of aquatic organisms such as fish and macroinvertebrates [40,42]. Conversely, a number of fish do not prefer to reside in the straight reach with the simple structure and high flow velocity [40]. Accordingly, in the present study, the fish densities were considerably higher in Sections 1, 3 and 4, which had strongly meandering channel morphologies, than in the relatively strait sections.

Second, deep pools have been found to play an important role in the breeding and growth of the fish community [42-45]. Deep pools support slow velocities and coarse substrates, which allow food to accumulate and increase bottom-food production. An important ecological characteristic of the Upper Yangtze fish fauna is the large proportion of bottom-dwelling fish with insectivorous feeding habits. Rhinogobio cylindricus, belonging to this ecological guild and dominant species in Mudong reach, preferred this type of habitat. Meanwhile, deep pools like those near Yuzui might act as a refuge from predators and major disturbances such as overfishing and intensive ship traffic. In addition, many small fish are well adapted to low-gradient, slow-flow habitats. Thus, some fish, such as Squalidus argentatus, Saurogobio dabryi, and Pelteobagrus fulvidraco preferred this type of habitat near Mudong Town. Harvey and Stewart [46] reported that minnows survived longer in pools than riffles and runs. Spina [47] also showed that trout selected locations based on depth and longitudinal position in the North Fork River (California, USA). Apart from this, more patches were found in Sections 6, 7, and 8 in August because a large number of fish larvae aggregated in the deep nearshore waters in the present study (Figure 5). The presence of fish larvae such as R. cylindricus, P. vachelli, and Hemiculter bleekeri near the shore might be a common phenomenon in temperate waters. Remaining close to the shore may make it easier to find a suitable settlement habitat and give the fish a more productive environment to grow in [48].

Third, fish formed tiny aggregations in December which could be attributed to their overwintering behavior. These fish are poikilothermic, so their body temperatures vary with the external environment. When water temperature declines from fall into winter, metabolic processes slow down, and the fish's abilities to swim, feed, avoid predators, and defend their locations also decline [39]. Therefore, fish may aggregate in deeper areas with slower water velocities to increase survivorship. This behavior has been observed in cyprinid fish and riverine salmonids $[49,50]$.

Furthermore, in this study, we found a higher fish density in August than in May and December, since many pelagic larval fish drift into the transitional zone and grow there during the flooding season $[7,51]$. Previous studies have reported that three spawning grounds in the national nature reserve for rare and endemic fish of the Upper Yangtze River were located upstream of the Mudong reach [51]. When the water level increased during the late spring and summer, at least 28 fish species-including four major Chinese carps, Sinibotia superciliaris, R. giurinus, Leptobotia elongate, Lepturichthys fimbriata, and C. guichenoti-spawned in the reserve [51,52].

The results and implications of this local study may also benefit other fields of science and aquatic environments. For example, Zhang et al. [53] demonstrated that the development of fisheries and biodiversity conservation for the past 70 years in Chinese inland waters could serve as a leading example for global inland aquatic biodiversity. A local study of both freshwater and marine environments can have implications for broader research on these environments in other regions. Kang et al. [54] exhibited that a study of a small region of the Terra Nova Bay Polynya $\left(<2000 \mathrm{~km}^{2}\right)$ could (i) help understand the vertical and horizontal distributions of krill and (ii) find correlations between the observed patterns and the dominant environmental attributes; their results led them to infer krill dynamics in the Ross Sea, Antarctica. In this context, we believe that cumulative localized research results can lead to the comprehensive realization on the relevant ecosystem.

\subsection{Species Compositions and Fish Sizes}

Many studies have reported that the impoundment of large dams in the Yangtze River result in substantial changes in the species compositions of upstream fish assemblages $[7,17,20]$. In the TGR, long-term catch data from the Mudong reach indicated that fish assemblage regime shifts had 
occurred in 2008 [20]. The present study also found that the relative abundance of dominant fish species was considerably different compared to that before the impoundment (1997-2002). For instance, C. guichenoti accounted for $30.0 \%$ of the fish abundance before the impoundment (1997-2002), but it dropped to $15.19 \%$ in $2006-2009$ and $<1 \%$ in 2017 [7]. The relative abundance of $C$. heterodon also showed a declining trend. However, the relative abundance of $R$. cylindricus increased in the Mudong reach, starting at $6.94 \%$ of the total individuals in 1997-2002 and increasing to $19.80 \%$ in $2006-2009$, then to $30 \%$ in 2017 [7]. The changes in the dominant fish populations resulted from the construction of the dams in the Lower Jinsha River, such as the Xiangjiaba Dam [55]. These dams blocked the spawning migration route of fish, such as $C$. guichenoti, which used to be the dominant fish in the upper Yangtze, but were decreased in population size. Thus, $R$. cylindricus which has similar niches and is a competitor to C. guichenoti started to occupy its habitats and replace it as the dominant species [56].

A predominance of small individuals ( $<20 \mathrm{~cm}$ long) in the Mudong reach was verified by the high proportion of lower TS values and smaller fish lengths sampled. Previous studies have reported that transition zones in highly regulated rivers could serve as nursery habitats for juveniles or small fish $[7,57,58]$. In this study, fish size from biological samples showed that the Mudong reach could serve as a nursery habitat for at least six fish species (R. cylindricus, R. typus, S. dabryi, S. gymnocheilus, Leiocassis crassilabris and X. boulengeri). Furthermore, overfishing in the Yangtze River for last several decades have resulted in decreased abundance of large fish, leading to high abundance of small fish. Perera et al. [59] found that the length distribution of P. fluvidraco in the TGR was slanted towards smaller sizes and the spawning population only consisted of age classes 1 and 2.

\subsection{Future Fish Monitoring and Conservation Suggestions for the Upper Yangtze River}

Over the past few decades, the Yangtze River has been suffering a severe crisis of aquatic biodiversity due to dramatically decreasing fish resources [60,61]. The annual catch from the Yangtze River was more than 420 thousand tons in the 1950s, but fell to less than 100 thousand tons by the 2010s [60]. In 2017, a 10-year fishing ban for all 332 aquatic biota in the Yangtze River was implemented to protect and restore aquatic resources. This ban was extended to all major natural water bodies in the Yangtze River Basin until 2021 [19]. Under this background, traditional research methods like a net sampling will be further limited so that non-lethal techniques will become a main monitoring method. Our study demonstrates the feasibility of using hydroacoustic techniques to quantify fish density and spatial distributions in the Upper Yangtze River. The results of this study provide important background knowledge to support fish resources management. However, further research is needed to measure the target strength for dominant species in the Upper Yangtze River to attain an accurate target strength-fish length relationship.

The Upper Yangtze River is one of the largest hydropower development areas in China. There are currently 17 huge dams in the mainstream of the Upper Yangtze River-nine are operational and eight are under construction - and eight new dams are being planned. In the $800 \mathrm{~km}$-long reach from Panzhihua to Yibin, for example, two large dams (Xiangjiaba Dam and Xiluodu Dam) have been constructed and another two (Baihetan Dam and Wudongde Dam) are under construction. When all four dams are operational, $95 \%$ of the free-flowing reach will be lost. Therefore, the transitional zone will become critical for fish species diversity in the Upper Yangtze River. Lastly, our results found that the meandering deep channels increase habitat heterogeneity and enhance fish abundance, and thus more attention should be paid to these areas in terms of conservation in highly regulated river systems.

Author Contributions: Conceptualization, P.L. and X.G. (Xin Gao); methodology, P.L. and X.G. (Xin Gao); validation, P.L.; formal analysis, P.L. and X.G. (Xingchen Gao); investigation, P.L., L.C., and X.G. (Xin Gao); data curation, P.L.; writing - original draft preparation, P.L. and C.W.; writing-review and editing, X.G. (Xin Gao) and M.K.; and visualization, P.L. and M.K. All authors have read and agreed to the published version of the manuscript.

Funding: This research was funded by the National Key Research and Development Program of China (No. 2018YFD0900806), the Open Project of Hubei Key Laboratory of Three Gorges Project for Conservation of Fishes (SXSN/4381), the National Natural Science Foundation of China (No. 51509239), and the Sino BON-Inland Water Fish Diversity Observation Network. 
Acknowledgments: We thank Zhenfei Xing, Chen Zhang, Wenjing Li, and Xingcheng Luo for their assistance with the field work. Thanks also to Noah Last for his English language editing. We also gratefully acknowledge the reviewers for their valuable comments and suggestions on our manuscript.

Conflicts of Interest: The authors declare no conflict of interest.

\section{References}

1. Cooke, S.J.; Martins, E.G.; Struthers, D.P.; Gutowsky, L.F.G.; Power, M.; Doka, S.E.; Dettmers, J.M.; Crook, D.A.; Lucas, M.C.; Holbrook, C.M.; et al. A moving target-Incorporating knowledge of the spatial ecology of fish into the assessment and management of freshwater fish populations. Environ. Monit. Assess. 2016, 188, 1-18. [CrossRef] [PubMed]

2. Esselman, P.C.; Allan, J.D. Relative influences of catchment- and reach-scale abiotic factors on freshwater fish communities in rivers of northeastern Mesoamerica. Ecol. Freshw. Fish 2010, 19, 439-454. [CrossRef]

3. Gerasimov, Y.V.; Borisenko, E.S.; Bazarov, M.I.; Stolbunov, I.A. Density and distribution of fish in a river with a pronounced heterogeneity of the environment: Hydroacoustic Survey. Inland Water Biol. 2019, 12, 69-75. [CrossRef]

4. Wagner, T.; Midway, S.R.; Whittier, J.B.; Deweber, J.T.; Paukert, C.P. Annual changes in seasonal river water temperatures in the eastern and western United States. Water 2017, 9, 90. [CrossRef]

5. Park, Y.-S.; Chang, J.; Lek, S.; Cao, W.; Brosse, S. Conservation strategies for endemic fish species threatened by the Three Gorges Dam. Conserv. Biol. 2003, 17, 1748-1758. [CrossRef]

6. De Oliveira, E.F.; Goulart, E.; Minte-Vera, C.V. Fish diversity along spatial gradients in the Itaipu Reservoir, Paraná, Brazil. Braz. J. Biol. 2004, 64, 447-458. [CrossRef]

7. Yang, S.; Gao, X.; Li, M.; Ma, B.; Liu, H.Z. Interannual variations of the fish assemblage in the transitional zone of the Three Gorges Reservoir: Persistence and stability. Environ. Boil. Fishes 2011, 93, 295-304. [CrossRef]

8. Muška, M.; Tušer, M.; Frouzová, J.; Mrkvička, T.; Ricard, D.; Sed'a, J.; Morelli, F.; Kubečka, J. Real-time distribution of pelagic fish: Combining hydroacoustics, GIS and spatial modelling at a fine spatial scale. Sci. Rep. 2018, 8, 5381. [CrossRef]

9. Simmonds, J.E.; Maclennan, D.N. Fisheries Acoustics: Theory and Practice, 2nd ed.; Blackwell: London, UK, 2005; p. 437.

10. Kang, M. Overview of the applications of hydroacoustic methods in South Korea and fish abundance estimation methods. Fish. Aquat. Sci. 2014, 17, 369-376. [CrossRef]

11. Pollom, R.A.; Rose, G.A. A global review of the spatial, taxonomic, and temporal scope of freshwater fisheries hydroacoustics research. Environ. Rev. 2016, 24, 333-347. [CrossRef]

12. Myers, N.; Mittermeier, R.A.; Mittermeier, C.G.; Da Fonseca, G.A.B.; Kent, J. Biodiversity hotspots for conservation priorities. Nature 2000, 403, 853-858. [CrossRef] [PubMed]

13. Qiao, Y.; Tang, X.; Brosse, S.; Chang, J. Chinese Sturgeon (Acipenser sinensis) in the Yangtze River: A hydroacoustic assessment of fish location and abundance on the last spawning ground. J. Appl. Ichthyol. 2006, 22, 140-144. [CrossRef]

14. Lian, Y.; Ye, S.; Godlewska, M.; Huang, G.; Wang, J.; Chen, S.; Zhao, X.; Du, X.; Liu, J.; Li, Z. Diurnal, seasonal and inter-annual variability of fish density and distribution in the Three Gorges Reservoir (China) assessed with hydroacoustics. Limnologica 2017, 63, 97-106. [CrossRef]

15. Li, J.; Zhang, H.; Lin, D.; Wu, J.; Wang, C.; Xie, X.; Wei, Q. Spatiotemporal distribution and assemblages of fishes below the lowermost dam in protected reach in the Yangtze River main stream: Implications for river management. BioMed Res. Int. 2016, 2016, 1-8. [CrossRef]

16. Guo, A.; Yuan, J.; Chu, T.; Lian, Q. Hydroacoustic assessment of fish resources in three reservoirs: The effects of different management strategies on fish density, biomass and size. Fish. Res. 2019, 215, 90-96. [CrossRef]

17. Lin, P.; Gao, X.; Liu, F.; Li, M.; Liu, H. Long-term monitoring revealed fish assemblage zonation in the Three Gorges Reservoir. J. Oceanol. Limnol. 2018, 37, 1258-1267. [CrossRef]

18. Wu, X.; Qin, J.; Xu, Y.; Ouyang, S.; Wu, X. Biodiversity decline of fish assemblages after the impoundment of the Three Gorges Dam in the Yangtze River Basin, China. Rev. Fish Biol. Fish. 2019, 29, 177-195. [CrossRef]

19. Chen, Y.; Qu, X.; Xiong, F.; Lu, Y.; Wang, L.; Hughes, R.M. Challenges to saving China's freshwater biodiversity: Fishery exploitation and landscape pressures. Ambio 2019, 49, 926-938. [CrossRef]

20. Gao, X.; Fujiwara, M.; Winemiller, K.O.; Lin, P.; Li, M.; Liu, H.Z. Regime shift in fish assemblage structure in the Yangtze River following construction of the Three Gorges Dam. Sci. Rep. 2019, 9, 4212. [CrossRef] 
21. Yi, B.L.; Yu, Z.T.; Liang, Z.X. Gezhouba Water Control Project and Four Famous Chinese Carps in the Yangtze River; Hubei Science \& Technology Press: Wuhan, China, 1988; p. 116.

22. Liu, L.H.; Wu, G.X.; Wang, Z.L. Reproduction ecology of Coreius Heterodon (Bleeker) and Coreius Guichenoti (Sauvage et Dabry) in the mainstream of the Changjiang River after the construction of Gezhouba Dam. Acta Hydrobiologia Sinica 1990, 14, 205-215.

23. The Website of National Hydrological and Rainfall Information. Available online: http://xxfb.mwr.cn/sq_ djdh.html (accessed on 31 December 2017).

24. Foote, K.G.; Knudsen, H.P.; Vestnes, G.; MacLennan, D.N.; Simmonds, E.J. Calibration of Acoustic Instruments for Fish Density Estimation: A Practical Guide; ICES Cooperative Research Report; ICES Cooperative Research: Copenhagen, Denmark, 1987; p. 144.

25. Aglen, A. Random Errors of Acoustic Fish Abundance Estimates in Relation to the Survey Grid Density Applied; FAO Fisheries Report; FAO Fisheries: Rome, Italy, 1983; pp. 293-298.

26. Godlewska, M.; Długoszewski, B.; Doroszczyk, L.; Jóźwik, A. The relationship between sampling intensity and sampling error-Empirical results from acoustic surveys in Polish vendace lakes. Fish. Res. 2009, 96, 17-22. [CrossRef]

27. Guillard, J.; Vergès, C. The repeatability of fish biomass and size distribution estimates obtained by hydroacoustic surveys using various survey designs and statistical analyses. Int. Rev. Hydrobiol. 2007, 92, 605-617. [CrossRef]

28. Yang, S.; Gao, X.; Ma, B.; Kong, Y.; Liu, H. Seasonal dynamics of fish community in Mudong section of the Three Gorges Reservoir of the Yangtze River, China. Chin. J. Appl. Environ. Biol. 2010, 16, 555-560.

29. Ding, R.H. The fishes of Sichuan, China; Sichuan Publishing House of Science and Technology: Chengdu, China, 1994; p. 641.

30. Balk, H.; Lindem, T. Sonar4 and Sonar5 Post Processing Systems, Operator Manual v5.9.4; University of Oslo: Oslo, Norway, 2004; p. 405.

31. Parker-Stetter, S.L.; Rudstam, L.G.; Sullivan, P.J.; Warner, D.M. Standard Operating Procedures for Fisheries Acoustic Surveys in the Great Lakes; Great Lakes Fisheries Commission Special Publication, 09-01; Great Lakes Fisheries Commission: Ann Arbor, MI, USA, 2009.

32. Tušer, M.; Kubečka, J.; Frouzová, J.; Jarolím, O. Fish orientation along the longitudinal profile of the Římov reservoir during daytime: Consequences for horizontal acoustic surveys. Fish. Res. 2009, 96, $23-29$. [CrossRef]

33. Frouzova, J.; Kubecka, J.; Balk, H.; Frouz, J. Target strength of some European fish species and its dependence on fish body parameters. Fish. Res. 2005, 75, 86-96. [CrossRef]

34. Rodríguez-Sánchez, V.; Encina-Encina, L.; Ruiz, A.R.; Sánchez-Carmona, R. Horizontal target strength of Luciobarbus sp. in ex situ experiments: Testing differences by aspect angle, pulse length and beam position. Fish. Res. 2015, 164, 214-222. [CrossRef]

35. De Robertis, A.; McKelvey, D.R.; Ressler, P.H. Development and application of an empirical multifrequency method for backscatter classification. Can. J. Fish. Aquat. Sci. 2010, 67, 1459-1474. [CrossRef]

36. Kang, M.; Furusawa, M.; Miyashita, K. Effective and accurate use of difference in mean volume backscattering strength to identify fish and plankton. ICES J. Mar. Sci. 2002, 59, 794-804. [CrossRef]

37. Korneliussen, R.J.; Ona, E. Synthetic echograms generated from the relative frequency response. ICES J. Mar. Sci. 2003, 60, 636-640. [CrossRef]

38. Abes, S.D.S.; Agostinho, A.A. Spatial patterns in fish distributions and structure of the ichthyocenosis in the Água Nanci stream, upper Paraná River basin, Brazil. Hydrobiologia 2001, 445, 217-227. [CrossRef]

39. Senay, C.; Macnaughton, C.J.; Lanthier, G.; Harvey-Lavoie, S.; Lapointe, M.; Boisclair, D. Identifying key environmental variables shaping within-river fish distribution patterns. Aquat. Sci. 2015, 77, 709-721. [CrossRef]

40. Nagayama, S.; Nakamura, F. The significance of meandering channel to habitat diversity and fish assemblage: A case study in the Shibetsu River, northern Japan. Limnology 2017, 19, 7-20. [CrossRef]

41. Hou, Y.; Yang, Z.; An, R.; Cai, L.; Chen, X.; Zhao, X.; Zou, X. Water flow and substrate preferences of Schizothorax wangchiachii (Fang, 1936). Ecol. Eng. 2019, 138, 1-7. [CrossRef]

42. Garcia, X.-F.; Schnauder, I.; Pusch, M.T. Complex hydromorphology of meanders can support benthic invertebrate diversity in rivers. Hydrobiology 2012, 685, 49-68. [CrossRef] 
43. Baird, I.G. Strength in diversity: Fish sanctuaries and deep-water pools in Lao PDR. Fish. Manag. Ecol. 2006, 13, 1-8. [CrossRef]

44. Lin, P.C.; Gao, X.; Zhu, Q.G.; Wang, T.; Liu, H.Z. Hydroacoustic survey on the spatial distribution pattern and day-night rhythmic behaviour of fishes in the Xiaonanhai reach of the upper Yangtze River. J. Appl. Ichthyol. 2013, 29, 1402-1407. [CrossRef]

45. Vašek, M.; Prchalová, M.; Říha, M.; Blabolil, P.; Čech, M.; Draštík, V.; Frouzová, J.; Jůza, T.; Kratochvíl, M.; Muška, M.; et al. Fish community response to the longitudinal environmental gradient in Czech deep-valley reservoirs: Implications for ecological monitoring and management. Ecol. Indic. 2016, 63, 219-230. [CrossRef]

46. Harvey, B.C.; Stewart, A.J. Fish size and habitat depth relationships in headwater streams. Oecologia 1991, 87, 336-342. [CrossRef]

47. Spina, A.P. Habitat partitioning in a patchy environment: Considering the role of intraspecific competition. Environ. Boil. Fishes 2000, 57, 393-400. [CrossRef]

48. Beldade, R.; Borges, R.; Gonçalves, E.J. Depth distribution of nearshore temperate fish larval assemblages near rocky substrates. J. Plankton Res. 2006, 28, 1003-1013. [CrossRef]

49. Brown, R.S.; Hubert, W.A.; Daly, S.F. A primer on winter, ice, and fish: What fisheries biologists should know about winter ice processes and stream-dwelling fish. Fisheries 2011, 36, 8-26. [CrossRef]

50. Wolter, C. Temperature influence on the fish assemblage structure in a large lowland river, the lower Oder River, Germany. Ecol. Freshw. Fish 2007, 16, 493-503. [CrossRef]

51. Jiang, W.; Liu, H.-Z.; Duan, Z.-H.; Cao, W.-X. Seasonal variation in drifting eggs and larvae in the upper Yangtze, China. Zool. Sci. 2010, 27, 402-409. [CrossRef] [PubMed]

52. Tang, X.L. Studies on early fish resources in Jiangjin cross-section in the Upstream of Yangtze River. Master's Thesis, Southwest University, Chongqing, China, 2010.

53. Zhang, H.; Wu, J.; Gorfine, H.; Shan, X.; Shen, L.; Yang, H.; Du, H.; Li, J.; Wang, C.; Zhou, Q.; et al. Inland fisheries development versus aquatic biodiversity conservation in China and its global implications. Rev. Fish Biol. Fish. 2020, 30, 637-655. [CrossRef]

54. Kang, M.; Fajaryanti, R.; Son, W.; Kim, J.H.; La, H.S. Acoustic setection of krill scattering layer in the Terra Nova Bay Polynya, Antarctica. Front. Mar. Sci. 2020, 7, 584550. [CrossRef]

55. Cheng, F.; Li, W.; Castello, L.; Murphy, B.R.; Xie, S. Potential effects of dam cascade on fish: Lessons from the Yangtze River. Rev. Fish Biol. Fish. 2015, 25, 569-585. [CrossRef]

56. Liu, F.; Wang, J.; Liu, H.-Z. Seasonal variations in food resource partitioning among four sympatric gudgeon species in the upper Yangtze River. Ecol. Evol. 2019, 9, 7227-7236. [CrossRef]

57. Terra, B.D.F.; Dos Santos, A.B.I.; Araújo, F.G. Fish assemblage in a dammed tropical river: An analysis along the longitudinal and temporal gradients from river to reservoir. Neotrop. Ichthyol. 2010, 8, 599-606. [CrossRef]

58. Buckmeier, D.L.; Smith, N.G.; Fleming, B.P.; Bodine, K.A. Intra-annual variation in river-reservoir interface fish assemblages: Implications for fish conservation and management in regulated rivers. River Res. Appl. 2013, 30, 780-790. [CrossRef]

59. Perera, H.A.C.C.; Rypel, A.L.; Murphy, B.R.; Li, Z.; Xia, Y.; Liu, J. Population characteristics of yellow catfish (Pelteobagrus fulvidraco) along the longitudinal profile of Three Gorges Reservoir, China. J. Appl. Ichthyol. 2013, 29, 1061-1066. [CrossRef]

60. Chen, D.; Xiong, F.; Wang, K.; Chang, Y. Status of research on Yangtze fish biology and fisheries. Environ. Boil. Fishes 2009, 85, 337-357. [CrossRef]

61. Huang, L.; Li, J. Status of freshwater fish biodiversity in the Yangtze River Basin, China. In Aquatic Biodiversity Conservation and Ecosystem Services; Nakano, S., Yahara, T., Nakashizuka, T., Eds.; Springer: Singapore, 2016; pp. 13-30.

Publisher's Note: MDPI stays neutral with regard to jurisdictional claims in published maps and institutional affiliations. 